\title{
Originals
}

\section{Impaired contraction and relaxation in aorta from streptozotocin-diabetic rats: role of polyol pathway}

\author{
N. E. Cameron and M.A. Cotter \\ Department of Biomedical Sciences, University of Aberdeen, UK
}

\begin{abstract}
Summary. The effects of 3 months streptozotocin-induced diabetes mellitus on contraction and relaxation of aorta were examined in vitro. A further diabetic group was treated with a novel sulphonylnitromethane-based aldose reductase inhibitor for 3 months following diabetes induction. Diabetes resulted in reduced maximal tension production, particularly for responses to phenylephrine $(p<0.001)$ and serotonin $(p<0.001)$. However, with aldose reductase inhibitor treatment, responses were in the non-diabetic range. The ratio of maximum contractions to noradrenaline and phenylephrine were $28 \%$ elevated by diabetes $(p<0.01)$, which may suggest increased $\alpha_{2}$-adrenoreceptor-mediated responses. Endothelium-independent relaxation to glyceryl trinitrate was unaffected by diabetes or treatment. By contrast, there were $38 \%$ deficits in endothelium-dependent relaxation to acetylcholine $(p<0.001)$ and $\mathrm{Ca}^{2+}$ ionophore $\mathrm{A} 23187$ $(p<0.001)$ with diabetes which were prevented by aldose reductase inhibitor treatment $(p<0.001)$. A $121 \%$ shift in the concentration giving a $50 \%$ maximum effect for acetylcholine towards lower sensitivity with diabetes $(p<0.001)$
\end{abstract}

was also largely corrected by treatment $(p<0.001)$. A nondiabetic group treated with aldose reductase inhibitor showed a $30 \%$ decrease in the $50 \%$ effective concentration for acetylcholine $(p<0.05)$. A $15 \%$ deficit in maximum relaxation to the ATP-sensitive $\mathrm{K}^{*}$ channel opener cromakalim for the diabetic group $(p<0.001)$ was prevented by aldose reductase inhibitor treatment $(p<0.01)$. We conclude that there are polyol pathway related abnormalities for contraction, some aspects of endothelium-independent relaxation, but particularly for endothelium-dependent relaxation in aorta from chronic streptozotocin-diabetic rats. If found in the appropriate circulatory beds, these could potentially contribute to the putative vascular basis of some of the complications of diabetes. Their amelioration could account for many of the beneficial effects of aldose reductase inhibitors.

Key words: Angiopathy, endothelium, endothelium-derived relaxing factor, nitric oxide, polyol pathway, aldose reductase, contraction, vascular smooth muscle, streptozotocin, diabetic rat.
In recent years a number of studies have suggested that the ability of vascular endothelium to relax smooth muscle [1] is impaired in human [2] and experimental diabetes. Animal models include streptozotocin (STZ) induced [3-9], or spontaneously diabetic rats [10-12] and alloxan-treated rabbits $[13,14]$. There are, however, conflicting reports in the literature, with normal relaxation for chemically-induced diabetes in dogs, rabbits and rats [15-17], and deficits for spontaneously, but not chemically-induced, diabetic rats [12]. In addition, several explanations have been proposed ranging from a deficit in production of the endothelium-derived relaxing factor (EDRF) nitric oxide (NO) [3-6], to abnormal synthesis of eicosanoid vasoconstrictors $[9,13]$. Furthermore, vascular reactivity may be enhanced in diabetic rats, perhaps because of increased $\alpha$-adrenoreceptor-mediated responses [18-20]. Altered reactivity may be a separate ef- fect rather than a consequence of abnormal endothelium function [21].

Vascular abnormalities probably contribute to the aetiology of many diabetic complications including neuropathy, nephropathy, retinopathy and myopathy $[22,23]$. For example, there is an early reduction in nerve blood flow in STZ-diabetic rats which gives rise to conduction deficits that may be restored by vasodilator treatment [24-26]. There is also substantial evidence that nerve function [27-29] as well as aspects of nephropathy [22], retinopathy [30] and myopathy [31,32] are preventable in diabetic rats by treatment with aldose reductase inhibitors (ARIs). There have been no reports that ARIs have haemodynamic effects in non-diabetic rats, which suggests that it is unlikely that they have a general vasodilator action. However, ARI treatment has been reported to ameliorate the reduction in nerve blood flow with diabetes 
[33], prevent increases in vascular permeability [34], and partially correct a deficit in depressor responses to arachidonic acid [35]. Clinical trials with the ARI tolrestat also produced statistically significant reductions in systolic and diastolic blood pressure in diabetic patients [36]. Thus, ARIs may have vascular-related effects which may contribute to their beneficial actions on diabetic complications. This report investigates that possibility by examining the effects of preventive ARI treatment on contraction and relaxation of rat aorta following 3 months of STZ-diabetes.

\section{Materials and methods}

Mature male Sprague-Dawley rats, aged 19 weeks, from the Aberdeen University colony were used. All animals were housed under the same conditions and had food and water ad libitum. Two groups were made diabetic with a single i.p. injection of STZ $(45 \mathrm{mg} / \mathrm{kg})$ in citrate buffer ( $\mathrm{pH} 4.5$ ). One group was not treated for 3 months, which acted as a diabetic control group. The other group was treated from induction of diabetes for 3 months with a novel ARI, (4-amino2,6-dimethylphenyl-sulphonyl) nitromethane, (ICI Pharmaceuticals, Macclesfield, Cheshire, UK) dissolved in the drinking water such that the final dose was approximately $21 \mathrm{mg} \cdot \mathrm{kg}^{-1} \cdot$ day $^{-1}$. This had no effect on the $250 \mathrm{~m} /$ day drunk by each diabetic rat. Onset and age-matched non-diabetic control groups were also used. A further group of non-diabetic rats was given ARI treatment for 3 months, the concentration in the drinking water being adjusted to the same final daily dose as for the treated diabetic group. Blood glucose levels and glycosuria were monitored weekly (Visidex II and Diastix; Ames, Slough, Bucks., UK) for diabetic rats. Final plasma glucose values were measured on samples taken when the rats were killed.

In final experiments, thoracic aortas were removed under $2-5 \%$ halothane anaesthesia, cleaned of fat and connective tissue, cut into $4 \mathrm{~mm}$ rings, then cut longitudinally to form rectangles which were mounted using small tissue clips in $20 \mathrm{ml}$ organ baths. They were bathed in modified Krebs-Ringer solution $\left(144.0 \mathrm{Na}^{+}, 5.0 \mathrm{~K}^{+}\right.$, $2.5 \mathrm{Ca}^{2+}, 1.1 \mathrm{Mg}^{2+}, 25.0 \mathrm{HCO}^{-}, 1.1 \mathrm{PO}_{4} 3-, 1.1 \mathrm{SO}_{4} 2-, 11.0 \mathrm{glu}-$ cose, in mmolll) gassed with $95 \% \mathrm{O}_{2} 5 \% \mathrm{CO}_{2}(\mathrm{pH} 7.35)$ at $37^{\circ} \mathrm{C}$. Tension was monitored using isometric transducers, the outputs being displayed on chart recorders. Resting tension was maintained at $1 \mathrm{~g}$. The aortas were allowed to equilibrate for $45 \mathrm{~min}$ and were then tested for contraction with $1 \mu \mathrm{mol} / /$ phenylephrine. They were then washed and left to equilibrate for a further 30 min. Bathing fluid was changed every 20-30 min except during cumulative doseresponse experiments. Relaxation was assessed against a background of precontraction by phenylephrine $(100-300 \mathrm{nmol} / \mathrm{l}) \mathrm{ad}-$ justed for individual tissue samples to give approximately $60 \%$ of maximal tension. At the end of the experiment, whilst still under tension, the length of tissue was measured with vernier callipers. Aortic rectangles were gently blotted to remove excess bathing medium, and weighed. Cross sectional areas were calculated from length and weight, assuming a tissue density of 1.05 [4], and developed tensions were expressed per cross sectional area.

Chemicals used came from the following sources: acetylcholine, $\mathrm{Ca}^{2+}$ ionophore A23187, serotonin, noradrenaline, phenylephrine, flurbiprofen and STZ were obtained from Sigma, (Poole, Dorset, UK). Glyceryl trinitrate, in $5 \mathrm{mg}$ tablets, was obtained from Aberdeen Royal Infirmary Pharmacy. ARI, cromakalim and $\mathrm{L}^{\mathrm{N}^{\mathrm{G}}}$ nitroarginine were gifts from ICI Pharmaceuticals.

\section{Tissue sugars and polyols and assessment of ARI efficacy}

Sciatic nerve and abdominal aorta polyol levels were estimated from samples taken immediately after dissection and frozen in liquid $\mathrm{N}_{2}$. Trimethyl-silyl derivatives were prepared from aqueous deproteinized extracts and analysed by gas chromatography [37]. The sci-
Table 1. Sciatic nerve sugar and polyol levels

\begin{tabular}{lrrll}
\hline Group & \multicolumn{1}{c}{$n$} & Glucose & Sorbitol & Fructose \\
\hline Control & 15 & $2.11 \pm 0.11$ & $0.170 \pm 0.010$ & $0.505 \pm 0.036$ \\
Control + ARI & 5 & $1.96 \pm 0.04$ & $0.021 \pm 0.002^{\mathrm{a}}$ & $0.113 \pm 0.008^{\mathrm{a}}$ \\
Diabetic & 10 & $15.03 \pm 2.16^{\mathrm{a}}$ & $2.721 \pm 0.220^{\mathrm{a}}$ & $8.083 \pm 0.655^{\mathrm{a}}$ \\
Diabetic + ARI & 9 & $16.79 \pm 1.02^{\mathrm{a}}$ & $0.072 \pm 0.003^{\mathrm{b}}$ & $0.661 \pm 0.041^{\mathrm{b}}$ \\
\hline
\end{tabular}

${ }^{a} p<0.001$ vs control group; ${ }^{b} p<0.001$ diabetic + ARI vs diabetic group

Values are means \pm SEM in nmolimg tissue wet weight

ARI, Aldose reductase inhibitor

atic nerve was used as a test tissue to ascertain the efficacy of polyol pathway blockade by ARI, as metabolites accumulate to high levels with diabetes. Results for the groups in this study are shown in Table 1. Compared to the control groups, sorbitol and fructose were elevated 16 -fold in the non-treated diabetic group. With ARI treatment, for controls, sorbitol was $12 \%$ and fructose was $22 \%$ of the normal values. In the ARI-treated diabetic group sorbitol levels were $42 \%$ of those for non-diabetic controls and fructose was within the normal range. Nerve glucose was increased eight-fold with diabetes and this was unaffected by ARI treatment. Taken together, these results suggest a high level of polyol pathway blockade by the ARI. Aortic tissue is unlike nerve in that sorbitol does not accumulate to a great extent. This appears to be because cells are relatively permeable to this metabolite which is lost to the circulation, thus, when galactose is used as a substrate for the pathway, galactitol accumulates to similar levels to those found in sciaticnerve and these may be reduced by ARI in a dose-dependent fashion [22]. Similar observations have been made for cardiac and skeletal muscle $[23,31,38]$. Sorbitollevels of the aorta were $0.020 \pm 0.005 \mathrm{nmol} / \mathrm{mg}$ wet weight in the non-diabetic controls $(n=14)$. This was increased to $0.068 \pm 0.009 \mathrm{nmol} / \mathrm{mg}$ wet weight with the non-treated diabetic group $(p<0.01, n=16)$. With ARI treatment sorbitol levels were $0.031 \pm 0.010 \mathrm{nmol} / \mathrm{mg}$ wet weight, not significantly different from controls, but reduced compared to the non-treated diabetic group $(p<0.05, n=12)$. In the ARI-treated control group, sorbitol levels were $0.010 \pm$ $0.005 \mathrm{nmol} / \mathrm{mg}$ wet weight $(n=5)$. This suggests that ARI treatment was effective in blocking aorta polyol pathway activity.

\section{Statistical analysis}

Results are expressed as group means \pm SEM. Data were subjected to one-way analysis of variance, and any statistically significant differences were assigned to individual between group comparisons using Student's $t$-tests and the Bonferroni correction for multiple comparisons (Instat; GraphPad, San Diego, Calif., USA). To avoid unnecessary multiple comparisons, data from the ARI-treated control group were not compared with data from either diabetic group.

\section{Results}

Rats were mature at the start of the study, onset controls weighed $501 \pm 12 \mathrm{~g}(n=17)$ and age-matched controls reached $538 \pm 13 \mathrm{~g}(n=12)$. Diabetic animals lost weight, being $358 \pm 15 \mathrm{~g}(n=22)$ without and $395 \pm 12 \mathrm{~g}(n=19)$ with ARI treatment. The ARI-treated non-diabetic group weighed $582 \pm 12 \mathrm{~g}(n=11)$. Plasma glucose was elevated by diabetes to $33.4 \pm 3.6 \mathrm{mmol} / \mathrm{l}$, and was unaffected by ARI treatment $(33.6 \pm 3.8 \mathrm{mmol} / \mathrm{l})$.

\section{Contractile responses}

There were no significant differences between onset and age-matched non-diabetic controls, and the data have been pooled for graphic presentation. Contractions of 


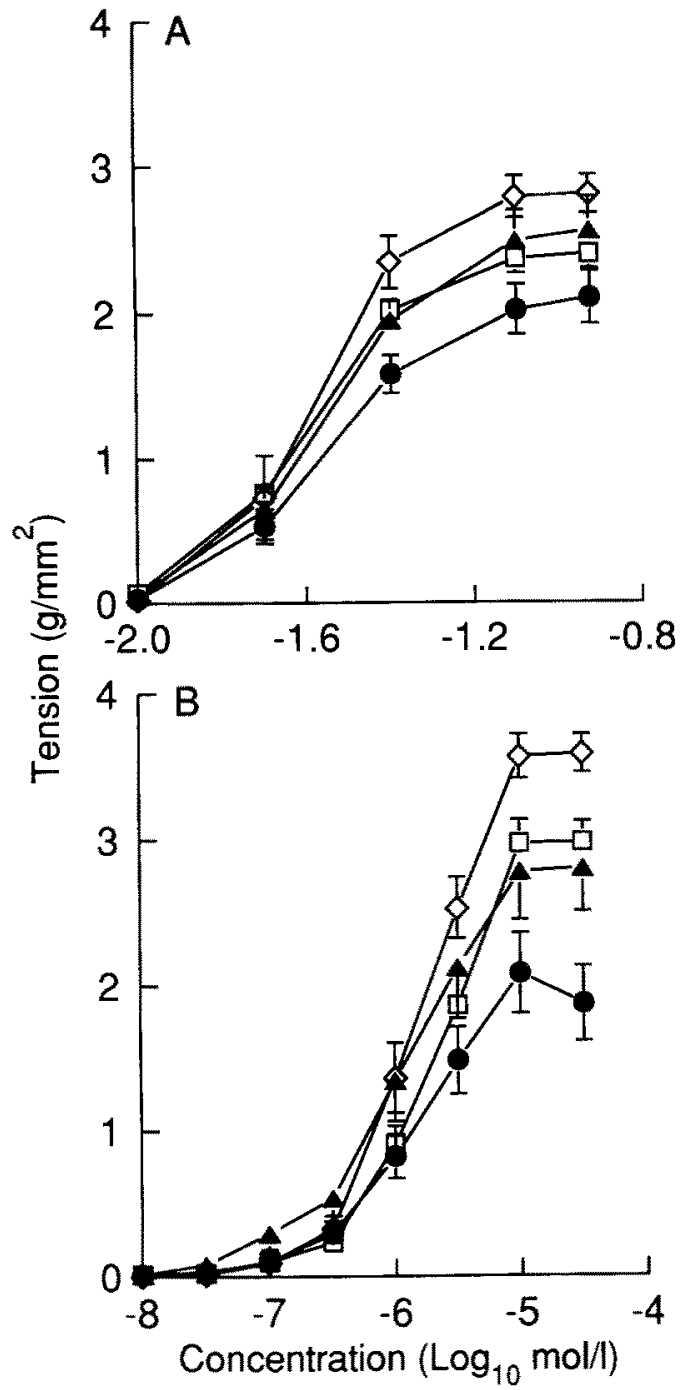

Fig.1. A, tension development of aortas in response to $\mathrm{K}^{+}$for control (onset $n=14$, age-matched $n=10, \square)$, diabetic $(n=16, \bullet)$, aldose reductase inhibitor. (ARI)-treated diabetic $(n=13, \boldsymbol{\Delta})$, and ARI-treated control $(n=9, \diamond)$ groups. B, serotonin responses for control (onset $n=13$, age-matched $n=10, \square$ ), diabetic $(n=15, \bullet$ ), ARI-treated diabetic $(n=15, \boldsymbol{\Delta})$ and ARI-treated controls $(n=11$, $\vartheta)$. Data are means \pm SEM

aorta from non-treated diabetic rats tended to be weaker than for controls. This was least apparent for $\mathrm{K}^{+}$contractures (Fig. 1A) where the only significant difference $(p<0.05)$ was seen at $40 \mathrm{mmol} / \mathrm{l} \mathrm{K}$. Data points for the ARI-treated diabetic group were closest to those of controls, but there were no significant effects of treatment compared to the diabetic group. ARI-treated controls did not show any significant differences compared to nontreated controls. There were no significant differences in the effective concentrations for a $50 \%$ maximal response $\left(\mathrm{EC}_{50}\right)$ which were $26.1 \pm 1.4,29.0 \pm 2.2,27.7 \pm 2.2$ and $27.8 \pm 1.9 \mathrm{mmol} / \mathrm{l}$ for control, diabetic, ARI-diabetic and ARI-control groups respectively.

A diminished maximum contractile response to serotonin (Fig.1B) was noted with non-treated diabetes $(p<0.001)$. Contractile force was variable, however, with around $33 \%$ of diabetic rats showing normal responses, whereas $67 \%$ had responses at least $1 \mathrm{SD}$ reduced from

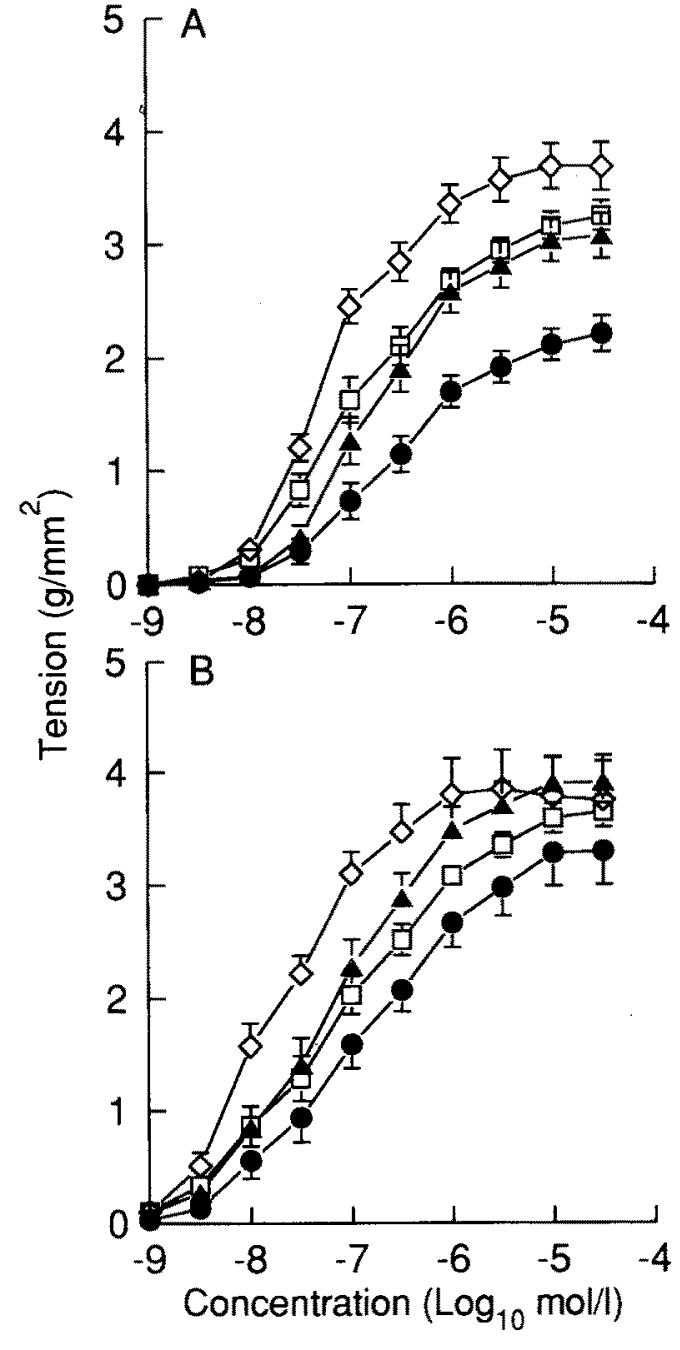

Fig. 2. A, B Tension development in response to phenylephrine (A) and noradrenaline (B) in aortas from control (onset $n=13$, agematched $n=10, \square)$, diabetic $(n=15, \bullet)$, aldose reductase inhibitor (ARI)-treated diabetic rats $(n=15, \boldsymbol{\Delta})$ and ARI-treated control rats $(n=11$ for phenylephrine, $n=6$ for noradrenaline, $\diamond)$. Data are means $\pm \mathrm{SEM}$

the normal range. This was not restricted to individual aortic rectangles, but was reproducible within a diabetic rat. Some specimens showed a tendency to relax at the highest concentration employed. Variability was also evident for the ARI-treated group, but the majority ( $74 \%$ ) of responses were in the normal range. There was a significant $(p<0.05)$ effect of ARI treatment only at the highest concentration $(30 \mu \mathrm{mol} / \mathrm{l})$. ARI-treated controls produced $19 \%$ greater maximal tension than non-treated controls $(p<0.05)$. There were no significant differences in the $\mathrm{EC}_{50}$ between groups, values ranging from $1.98 \pm 0.34$ to $2.78 \pm 0.80 \mu \mathrm{mol} / \mathrm{l}$.

Responses to phenylephrine are shown in Figure $2 \mathrm{~A}$. With diabetes, there was a $28 \%$ reduction in maximum tension production $(p<0.001)$, and significant differences from control values between $30 \mathrm{nmol} / \mathrm{l}(p<0.05)$ and $30 \mu \mathrm{mol} / \mathrm{l}(p<0.001)$. ARI treatment largely prevented this, from $300 \mathrm{nmol} / 1(p<0.05)$ to $30 \mu \mathrm{mol} / 1(p<0.01)$. The ARI-treated diabetic group showed no significant differences from controls. ARI-treated controls did not 
1014

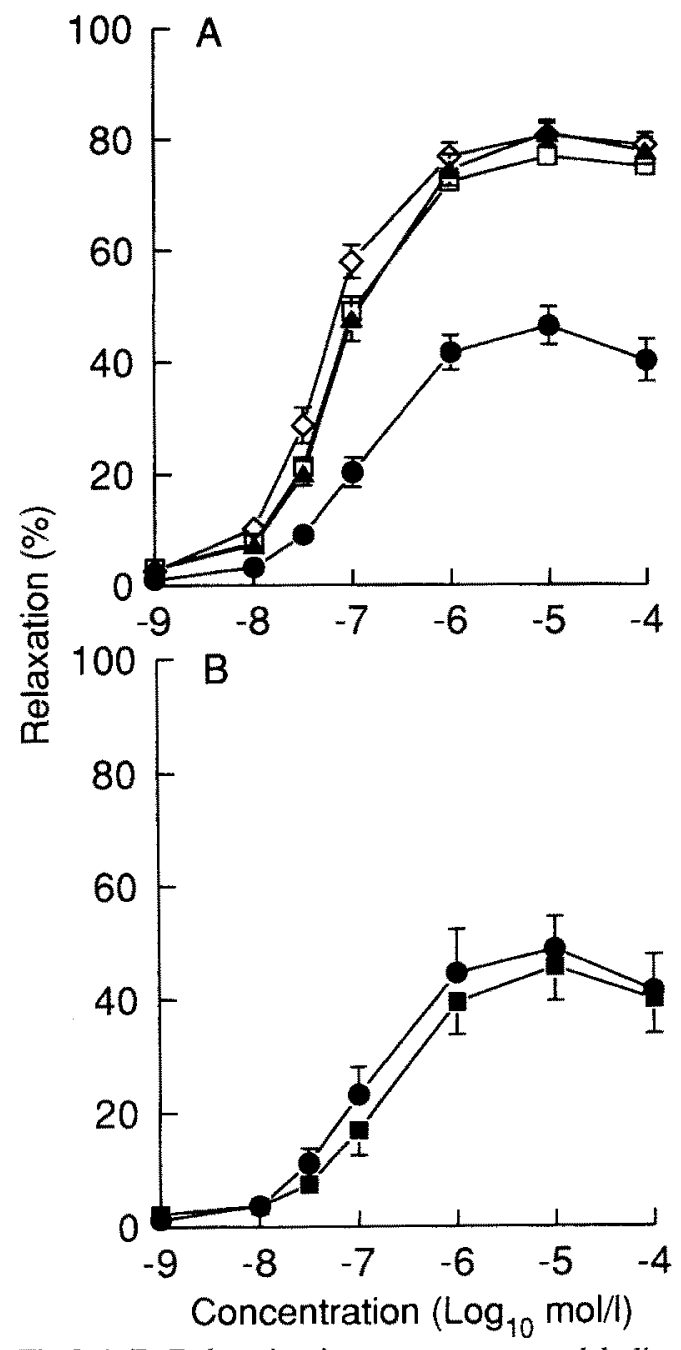

Fig. 3.A,B Relaxation in response to acetylcholine after pre-contraction with phenylephrine. A, controls (onset $n=14$, agematched $n=10 ; \square)$, diabetic controls $(n=22 ; \mathbf{0})$, aldose reductase inhibitor (ARI)-treated diabetic group $(n=19 ; \mathbf{A})$, ARI-treated non-diabetic group $(n=11 ; 0)$. B, diabetic controls without $(n=10$; -) or after $30 \mathrm{~min}$ pre-treatment with $5 \mu \mathrm{mol} / \mathrm{l}$ flurbiprofen $(n=10$, - ). Data are means \pm SEM

differ significantly from non-treated controls for maximal contraction, however, responses for intermediate concentrations of phenylephrine $(100 \mathrm{nmol} / \mathrm{l}$ to $10 \mu \mathrm{mol} / \mathrm{l})$ were significantly greater $(p<0.05)$. There were no significant effects on $\mathrm{EC}_{50}$ which ranged from $69 \pm 11 \mathrm{nmol} / \mathrm{l}$ for $\mathrm{ARI}-$ treated controls to $313 \pm 63 \mathrm{nmol} / /$ for non-treated diabetes. In the same tissue samples, responses to noradrenaline were also measured (Fig. 2B). No clear deficit with diabetes was apparent, and there were no significant differences from controls. The ARI-treated diabetic group also did not differ from non-diabetic controls, however, there was an increase in tension production compared with diabetic controls between 0.3 and $3 \mu \mathrm{mol} / 1(p<0.05)$. There was no significant effect of ARI-treatment on control maximum contraction, however, at intermediate concentrations $(30 \mathrm{nmol} / \mathrm{l}$ to $1 \mu \mathrm{mol} / \mathrm{l})$ of noradrenaline responses in the ARI-treated group were enhanced $(p<0.05)$. There were no significant differences in $\mathrm{EC}_{50}$.
N.E. Cameron and M.A. Cotter: Aorta contraction and relaxation

The ratio of maximum tension production stimulated by noradrenaline compared to phenylephrine was $1.431 \pm 0.092$ for the diabetic group, whereas for non-diabetic controls it was $1.116 \pm 0.029(p<0.01)$. For ARItreated diabetic rats, the ratio was $1.276 \pm 0.057$, not significantly different from either group. For ARI-treated controls, the ratio was the same as for non-treated controls $(1.115 \pm 0.030)$.

\section{Relaxation}

Maximum endothelium-dependent relaxation was $38 \%$ impaired $(p<0.001)$ in diabetic aorta when stimulated with acetylcholine (Fig. $3 \mathrm{~A}$ ). This was prevented by ARI treatment $(p<0.001)$, the data points showing no significant departures from normal. Maximal relaxation was not affected in ARI-treated controls, although relaxations were significantly greater $(p<0.05)$ between $30 \mathrm{nmol} / \mathrm{A}$ and $100 \mathrm{nmol} / \mathrm{l}$ compared to non-treated controls. There was a $121 \%$ shift in $\mathrm{EC}_{50}$ towards lower sensitivity with diabetes (75.2 \pm 5.1 vs $166.1 \pm 15.3 \mathrm{nmol} / 1, p<0.001)$, which was largely $(75 \%)$ prevented by ARI treatment (98.0 $\pm 7.4 \mathrm{nmol} / \mathrm{l}, p<0.001)$. For ARI-treated controls there was a small ( $30 \%$ ) shift in $\mathrm{EC}_{50}$ towards greater sensitivity $(52.6 \pm 5.3 \mathrm{nmol} / 1, p<0.05)$ compared to nontreated controls.

Maximum relaxation to acetylcholine in a subset of the diabetic group was not affected by pre-incubation for $30 \mathrm{~min}$ with a cyclooxygenase inhibitor $(5 \mu \mathrm{mol} / \mathrm{l}$ flurbiprofen) (Fig. 3B). However, there was a $61 \%$ increase in $\mathrm{EC}_{50}(p=0.0031$, paired $t$-test $)$ from $142.2 \pm 23.1$ to $229.3 \pm 28.6 \mathrm{nmol} / \mathrm{l}$. Acetylcholine relaxations were not found after the endothelium had been removed (not shown), and in intact aorta from both control and diabetic rats, maximal responses to $10 \mu \mathrm{mol} / 1$ acetylcholine were completely reversed by $10 \mu \mathrm{mol} / / \mathrm{L}-\mathrm{N}^{\mathrm{G}}$-nitro arginine [39].

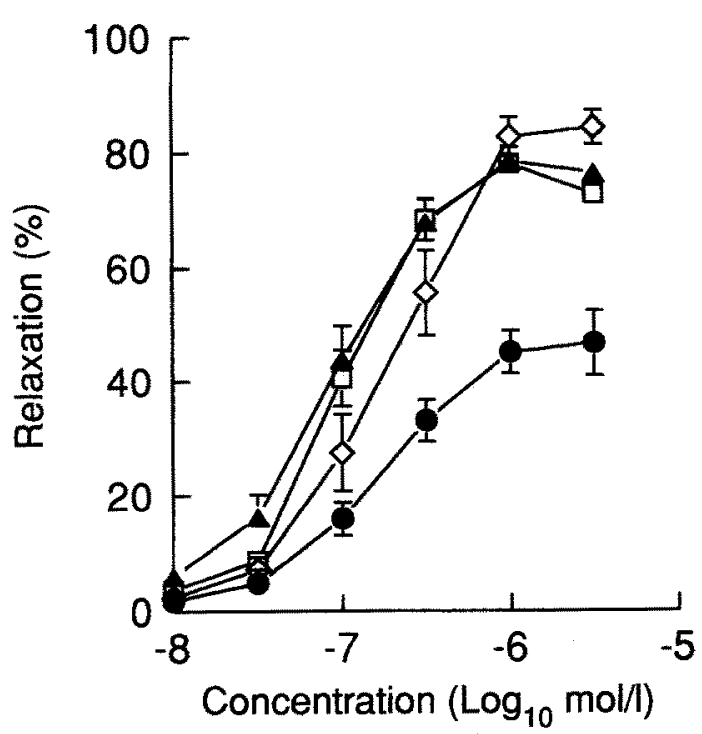

Fig.4. Relaxation in response to $\mathrm{Ca}^{2+}$ ionophore $\mathrm{A} 23187$ after pre contraction with phenylephrine. Controls (onset $n=10$, agematched $n=8 ; \square)$, diabetic controls $(n=14, \bullet)$, aldose reductase inhibitor (ARI)-treated diabetic rats $(n=12, \Delta)$ and ARI-treated controls $(n=6,0)$. Data are means \pm SEM 


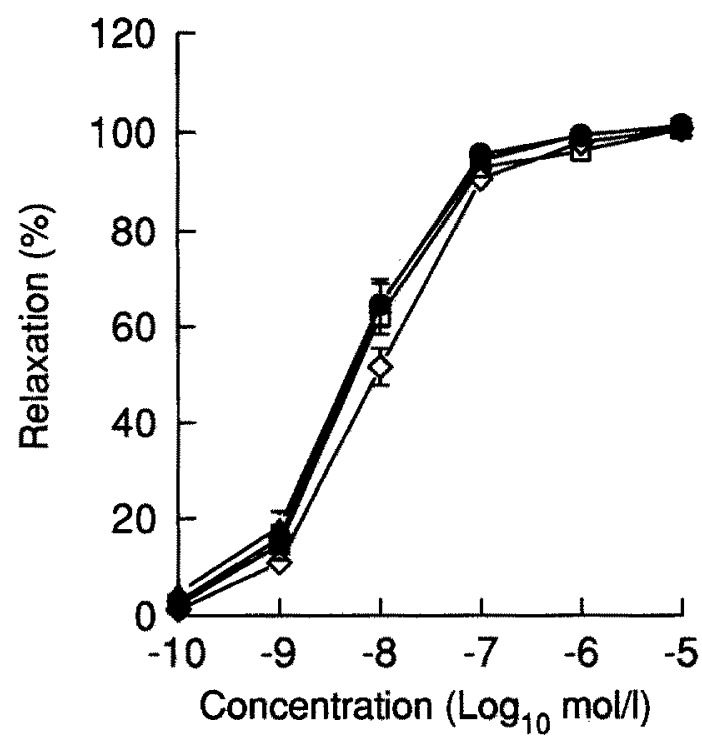

Fig.5. Relaxation in response to glyceryl trinitrate after pre contraction with phenylephrine. Controls (onset $n=10$, age-matched $n=9$; $\square)$, diabetic controls $(n=10, \bullet)$, aldose reductase inhibitor (ARI)treated diabetic rats $(n=10, \boldsymbol{\Delta})$ and ARI-treated controls $(n=6 ; 0)$. Data are means \pm SEM

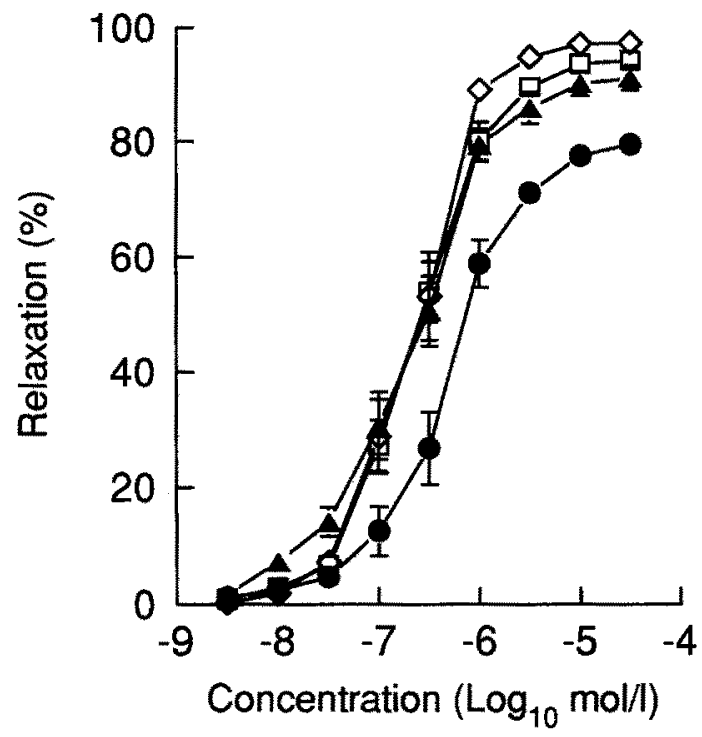

Fig.6. Relaxation in response to cromakalim after pre-contraction with phenylephrine. Controls (onset $n=10$, age-matched $n=10$; $\square)$, diabetic controls $(n=11,0)$, aldose reductase inhibitor (ARI)treated diabetic rats $(n=14, \boldsymbol{\Delta})$, and ARI-treated controls ( $n=10$, o). Data are means \pm SEM

Concentration-response curves for relaxation with $\mathrm{Ca}^{2+}$ ionophore A23187 are shown in Figure 4. Ionophore-mediated relaxations were similar in magnitude to those seen for acetylcholine, and provide evidence for an ARI-preventable diabetic deficit of around 38\% $(p<0.001$ for the control and ARI-treated diabetic vs the non-treated diabetic group). There were no significant differences between ARI-treated and non-treated controls. $\mathrm{EC}_{50}$ values (range $129 \pm 27$ to $291 \pm 89 \mathrm{nmol} /$ ) were not significantly affected by diabetes or treatment.
There were no significant between-group differences in relaxation mediated by glyceryl trinitrate (Fig.5) for either $\mathrm{EC}_{50}$ (range $5.7 \pm 1.1$ to $7.1 \pm 1.5 \mathrm{nmol} / 1$ ) or maximum relaxation (range $100.4 \pm 0.7 \%$ to $102.3 \pm 1.0 \%$ ).

Responses to the ATP-sensitive $\mathrm{K}^{+}$channel opener cromakalim are shown in Figure 6. This resulted in a maximum $91-97 \%$ relaxation of control, ARI-treated diabetic and ARI-treated control aortas at higher concentrations. However, in non-treated diabetic aortas the maximum relaxation was approximately $80 \%$, significantly reduced compared to the control or ARI-treated diabetic groups ( $p<0.001$ and $p<0.01$, respectively). ARI treatment had no effect on cromakalim-induced relaxation in non-diabetic rats. There were no significant differences in $\mathrm{EC}_{50}$ which were in the range of $279 \pm 54$ (ARItreated controls) to $519 \pm 87 \mathrm{nmol} / \mathrm{l}$ (non-treated diabetic group).

\section{Discussion}

The data show that ARI treatment can partially prevent contraction and almost completely prevent relaxation deficits in aorta from diabetic rats, without affecting hyperglycaemia or body weight loss. This has not previously been demonstrated. It is unlikely that diabetic changes resulted from a non-specific cytotoxic effect of STZ, because both contraction and relaxation deficits may be reversed by insulin treatment [7], and have been demonstrated in genetically susceptible diabetic BB-Wistar rats [10-12].

Contractions tended to be weaker with diabetes, particularly for phenylephrine and serotonin, without significant changes in sensitivity as reflected by $\mathrm{EC}_{50}$ values. This partially agrees with some other reports in the literature $[7,16,40,41]$, although sensitivity may vary with diabetes duration [42]. For noradrenaline, there was no significant deficit with diabetes. There have been reports of decreased responses [7, 16, 43], no effect [17], and increased sensitivity and/or contractile force $[4,18,44]$. While disagreements may depend on diabetes duration and severity, elevation of the noradrenaline/phenylephrine tension ratio supports the notion of increased $\alpha_{2}$-mediated responses $[18,19]$. One possible explanation is that diabetes caused changes in adrenoreceptor expression. ARI-treatment may have had a partial preventive effect, although statistically the results were equivocal. In another system, the ARI ponalrestat prevented an increase in myocardial $\beta$-receptor-mediated sensitivity in diabetic rats [45]. An alternative explanation is that $\alpha$-adrenoreceptor-mediated contraction is partially offset by stimulation of EDRF release. $\alpha_{2}$ stimulation normally evokes fairly equal contraction and relaxation so its contribution is minimized. However, with endothelial damage or dysfunction, a net contraction is produced which is additive to the $\alpha_{1}$ component when both are stimulated by noradrenaline. This view is supported by the data of Wakabayashi et al. [19] who compared responses to an $\alpha_{2}$ agonist in aorta with and without endothelium from diabetic and non-diabetic rats.

The reasons for reduced tension production with diabetes are unclear, particularly as results were agonist-dependent. Cardiac and skeletal muscle show impaired $\mathrm{Ca}^{2}$ * 
handling by sarcolemma and sarcoplasmic reticulum [4648], and the functional consequences of this are prevented by ARI treatment $[31,32]$. Contractile responses of aorta from diabetic rats show increased susceptibility to low extracellular $\mathrm{Ca}^{2+}$, indicating greater reliance on this source [44], and release from intracellular stores may also be impaired [49]. Since contractile strength was normal in the ARI-treated diabetic group, it is plausible that a polyol pathway related deficit in $\mathrm{Ca}^{2+}$ homeostasis could affect tension production. Interpretation is complicated, however, by the evidence that aorta from ARI-treated nondiabetic rats tended to produce greater tensions than nontreated controls, even when the data were normalized for tissue cross sectional area. An explanation is not obvious, but it could reflect a polyol pathway influence on $\mathrm{Ca}^{2+}$ handling even in normoglycaemia.

The reduction in endothelium-dependent relaxation is in agreement with several studies on aorta from STZ-diabetic rats [3-7], although others have failed to find a deficit $[12,16,17,21]$. The cause for the discrepancy is unclear, however, age and diabetes severity may be factors. The largest effect was evident when diabetes was induced in mature male rats [4]; a similar model was used in this investigation. Genetically susceptible BB-Wistar rats develop insulin-dependent diabetes when they are relatively mature, and all studies found impaired endothelium-dependent responses [10-12].

The cause of the endothelial deficit is unknown. There have been reports of patchy aortic endothelium damage $[4,12]$, and marked morphological changes have been noted in cerebral arterioles, including $20 \%$ necrosis of endothelial cells and mitochondrial swelling, after 4 weeks of STZ-diabetes [50]. However, functional defects of aorta, without obvious damage, have also been described $[3,6]$. Thus, metabolic abnormalities may be the prominent early cause of dysfunction. In rabbit aorta and rat cerebral arterioles, hyperglycaemia induces abnormal endothelial production of $\mathrm{PGH}_{2} / \mathrm{TxA}_{2}$ in response to acetylcholine the result of which causes contraction to oppose relaxation. $\mathrm{Ca}^{2+}$ ionophore $\mathrm{A} 23187$ does not evoke this response, and it may be prevented by an appropriate receptor blocker or cyclooxygenase inhibitor [9, 13]. The abnormality may even be induced in non-diabetic rabbit aorta in vitro by exposure to elevated glucose levels for several hours [51]. This mechanism is not responsible for dysfunction in diabetic rat aorta, as flurbiprofen did not improve relaxation, and there was a deficit for $\mathrm{Ca}^{2+}$ ionophore A23187, which agrees with a previous report [11]. Responses to glyceryl trinitrate were unaffected by diabetes, in agreement with other in vitro studies employing nitrodilators $[4,5,11]$, with one exception [12]. Thus, the data suggest that the abnormality relates to the production/release of NO, rather than to deficits in acetylcholine receptor/transduction or smooth muscle guanylate cyclase systems.

ARI treatment almost completely prevented endothelium-dependent abnormalities. There are several mechanisms which potentially explain this effect. Endothelium possesses polyol pathway activity, and, when cultured under high glucose conditions, cells accumulate sorbitol [52]. Aldose reductase requires NADPH as a cofactor [22].
Thus, when polyol pathway flux is enhanced by hyperglycaemia, competition with other NADPH-requiring enzymes will occur. This results, for example, in diminished levels of reduced glutathione (GSH) in several tissues [22]. NADPH is a cofactor for NO synthase, which controls production of NO from L-arginine [53] and would, therefore, be subjected to competition from the polyol pathway leading to deficits in endothelium-dependent relaxation. An indication that this might occur even for modest levels of glucose availability is given by the shift in acetylcholine $\mathrm{EC}_{50}$ values for non-diabetic controls with and without ARI treatment. Tissue ARI levels remain elevated long after treatment has ceased and plasma levels decline, presumably due to binding to aldose reductase [54]. Thus, it is likely that the polyol pathway remained inhibited in aortas from ARI-treated controls during the experiments. The $11 \mathrm{mmol} / \mathrm{l}$ glucose in the Krebs-Ringer solution should have provided a background polyol pathway flux to influence NO production, and inhibition would be expected to enhance sensitivity to agonists.

Another polyol-pathway-related change that could influence relaxation concerns a reduction in ATP synthesis, because agonist-stimulated EDRF release requires metabolic energy. Thus, inhibitors of both oxidative and glycolytic metabolism reduce NO synthesis in aorta from nondiabetic rabbits and rats, and cultured porcine endothelial cells [55-57]. When polyol pathway flux is high, glucose is diverted through the pentose phosphate shunt [22]. This process requires ATP, and for each molecule of glucose that takes this route, there is a net deficit of three molecules of ATP [58]. This deficit in energy metabolism with diabetes may be sufficient to impair NO production.

Decreased levels of GSH as a result of polyol pathway activity, and other diabetic changes including reduced superoxide dismutase which depends in part on the GSH abnormality [59], compromise tissue protection against oxidative stress and superoxide radicals. Cultured human endothelial cells in a high glucose concentration medium showed diminished glutathione-redox-cycle-related handling of peroxide, which was ameliorated by ARI treatment [60]. In addition, auto-oxidative glycosylation of proteins would be expected to generate oxygen free radicals [61]. Endothelium from diabetic rats is abnormally sensitive to superoxide damage [4]. Superoxide also breaks down NO [62], and in vitro addition of superoxide dismutase partly restores endothelium-dependent relaxation in aorta from diabetic rats [6]. Thus, cumulative effects of diabetes on endothelial integrity and function are likely, in part related to polyol pathway flux.

A longer term mechanism concerns formation of advanced glycosylation end products (AGEs). Chemically, these can act to quench NO. After 2 months of diabetes, blood pressure responses to acetylcholine and glyceryl trinitrate are impaired in rats [63]. Similar functional deficits have been noted for diabetic patients [64]. In diabetic rats this may be prevented by aminoguanidine treatment, which inhibits AGE formation [63]. Unfortunately, interpretation may be somewhat more complex, as recent work suggests that aminoguanidine also has ARI activity [65]. However, the direct (fructose) and indirect (fructose 6- 
phosphate and pentoses) products of polyol pathway activity are considerably more reactive than glucose in forming AGEs. Thus, ARIs could slow the development of AGE-related endothelial dysfunction, such as intracellular NO quenching and potentially deleterious effects for enzymes such as NO synthase.

The finding of an impairment in relaxation to the ATPsensitive $\mathrm{K}^{+}$channel opener cromakalim with diabetes is in agreement with a previous study [66], but is difficult to account for. It could reflect a relative paucity of ATP-sensitive $\mathrm{K}^{+}$channels, or an alteration in the mechanisms relating hyperpolarization to closure of voltage-dependent $\mathrm{Ca}^{2+}$ channels, or indeed a defect in the $\mathrm{Ca}^{2+}$ channels themselves. It has been suggested that diabetes enhances the activity of $\mathrm{Ca}^{2+}$ channels in vascular smooth muscle [67]. Whether this deficit would have functional consequences is unclear. ATP-sensitive $\mathrm{K}^{+}$channels could have a protective role when intracellular ATP levels are low [68], for example due to ischaemia, and subsequent vasodilation when channels open could be beneficial for tissue perfusion. This would suggest that under some circumstances diabetic tissues might be more susceptible to ischaemic damage, and that ARI treatment might provide protection via this mechanism.

If the effects seen for aorta generalize to resistance vessels in some vascular beds, then they could contribute to the complications of diabetes. In vivo measurements on conscious rats show that after 4 weeks of diabetes the reduction in hindlimb vascular resistance following bradykinin and enothelin-1 stimulation of endothelium is attenuated, as is the increase in vascular resistance due to infusion of the NO synthesis blocker $\mathrm{N}^{\mathrm{G}}$-nitro-L-arginine methyl ester $[69,70]$. For sciatic nerve, endoneurial blood flow is $40 \%$ reduced within one week of diabetes induction [24]. Myocardial perfusion is also impaired by diabetes [71]. Vasodilator treatment prevents nerve conduction deficits and some of the contractile changes in hindlimb skeletal muscles [24-26]. These are also prevented by ARI treatment $[31,32]$. This suggests that an important mechanism of ARI action in these tissues could be to correct polyol pathway related vascular dysfunction, particularly of the endothelium. A plausible conclusion is that this could explain the beneficial actions of ARIs in ameliorating diabetic complications such as neuropathy, at least in experimental models. Recent work has emphasised that many of the metabolic events of diabetes cause vascular abnormalities $[24,34,63]$, thus, the current dogmatic distinction between "metabolic" and "vascular" aetiologies of diabetic complications is becoming increasingly untenable.

Acknowledgements. We thank Dr. F. Carey of Imperial Chemical Industries for valuable discussion and support, and for supplying the ARI, and D. Mirrlees and Ms J. Stafford for polyol analysis.

\section{References}

1. Furchgott RF (1983) Role of endothelium in responses of vascular smooth muscle. Circ Res 53:557-573

2. Saenz de Tejada I, Goldstein I, Azadzoi K, Krane RJ, Cohen RA (1989) Impaired neurogenic and endothelium-mediated relaxa- tion of penile smooth muscle from diabetic men with impotence. N Eng J Med 320: 1025-1030

3. Oyama Y, Kawasaki H, Hattori Y, Kanno M (1986) Attenuation of endothelium-dependent relaxation in aorta from diabetic rats. Eur J Pharmacol 131: 75-78

4. Peiper GM, Gross GJ (1988) Oxygen free radicals abolish endothelium-dependent relaxation in diabetic rat aorta. Am J Physiol 255: H825-H833

5. Kamata K, Miyata N, Kasuya Y (1989) Impairment of endothelium-dependent relaxation and changes in levels of cyclic GMP in aorta from streptozotocin-induced diabetic rats. BrJ Pharmacol 97:614-618

6. Hattori Y, Kawasaki H, Kazuhiro A, Kanno M (1991) Superoxide dismutase recovers altered endothelium-dependent relaxation in diabetic rat aorta. Am J Physiol 261: H1086-H1094

7. Takiguchi Y, Satoh N, Hashimoto H, Nakashima M (1989) Reversal effect of thyroxine on altered vascular reactivity in diabetic rats. J Cardiovasc Pharmacol 13:520-524

8. Mahan WG (1989) Impairment of endothelium-dependent dilation of cerebral arterioles during diabetes mellitus. Am J Physiol 256: H621-H625

9. Mahan WG, Simmons LK, Sharpe GM (1991) Mechanism of impaired responses of cerebral arterioles during diabetes mellitus. Am J Physiol 260: H319-H326

10. Meraji S, Jayakody L, Senaratne MPJ, Thomson ABR, Kappagoda $T$ (1987) Endothelium-dependent relaxation in aorta of $B B$ rat. Diabetes 36: 978-981

11. Durante W, Sen AK, Sunahara FA (1988) Impairment of endothelium-dependent relaxation in aortae from spontaneously diabetic rats. Br J Pharmacol 94: 463-468

12. Kappagoda T, Jayakody L, Rajotte R, Tomson ABR, Senaratne MPJ (1989) Endothelium-dependent relaxation to acetylcholine in the aorta of streptozotocin induced diabetic-rat. Clin Invest Med 12: 187-193

13. Tesfamariam B, Jakubowski JA, Cohen RA (1989) Contraction of diabetic rabbit aorta caused by endothelium-derived $\mathrm{PGH}_{2}$ TxA 2 . Am J Physiol 257: H1327-H1333

14. Abiru T, Watanabe Y, Kamata K, Miyata N, Katsuya Y (1990) Decrease in endothelium-dependent relaxation and levels of cyclic nucleotides in aorta from rabbits with alloxan-induced diabetes. Res Commun Chem Pathol Pharmacol 68: 13-25

15. Gebremedhin D, Koltai MZ, Pogatsa G, Maygar K, Hadhazy P (1987) Differential contractile responsiveness of femoral arteries from healthy and diabetic dogs: role of endothelium. Arch Int Pharmacodyn 288: 100-108

16. Head RJ, Longhurst PA, Panek RL, Stitzel RE (1987) A contrasting effect of the diabetic state upon the contractile responses of aortic preparations from the rat and rabbit. Br. J Pharamcol 91: 275-286

17. Mulhern M, Docherty JR (1989) Effects of experimental diabetes on the responsiveness of rat aorta. Br J Pharmacol 97: $1007-1012$

18. Scarborough NL, Carrier GO (1983) Increased alpha-2 adrenoceptor mediated vascular contraction in diabetic rats. J Autonom Pharmacol 3:177-183

19. Wakabayashi I, Hatake K, Kimura N, Kakishita E, Nagai K (1987) Modulation of vascular tonus by the endothelium in experimental diabetes. Life Sci 40; 643-648

20. Agrawal D, McNeill JH (1987) Vascular responses to agonists in rat mesenteric artery from diabetic rats. Can J Physiol Pharmacol 65: $1484-1490$

21. Harris KH, MacLeod KM (1988) Influence of the endothelium on contractile responses of arteries from diabetic rats. Eur $J$ Pharmacol 153: 55-64

22. Dvornik D (1987) Hyperglycemia in the pathogenesis of diabetic complications. In: Porte D (ed) Aldose reductase inhibition. An approach to the prevention of diabetic complications. Biomediacal Information Corporation, New York pp 69-151

23. Cotter MA, Cameron NE, Lean D, Robertson S (1989) Effects of long-term streptozotocin diabetes on the contractile and histochemical properties of rat muscles. Q J Exp Physiol 74: 65-74 
24. Cameron NE, Cotter MA, Low PA (1991) Nerve blood flow in early experimental diabetes in rats: relation to conduction deficits. Am J Physiol 261: E1-E8

25. Cameron NE, Cotter MA, Robertson S (1992) Angiotensin converting enzyme inhibition prevents the development of muscle and nerve dysfunction and stimulates angiogenesis in streptozotocin-diabetic rats. Diabetologia 35: 12-18

26. Cameron NE, Cotter MA, Ferguson K, Robertson S, Radcliffe MA (1991) Effects of chronic $\alpha$-adrenergic receptor blockade on peripheral nerve conduction, hypoxic resistance, polyols, $\mathrm{Na}^{+}$$\mathrm{K}^{+}$-ATPase activity and vascular supply in STZ-D rats. Diabetes 40: $1652-1658$

27. Mayer JH, Tomlinson DR (1983) Prevention of defects of axonal transport and nerve conduction by oral administration of myoinositol or an aldose reductase inhibitor in streptozotocindiabetic rats. Diabetologia 25: 433-438

28. Cameron NE, Leonard MB, Ross I, Whiting P (1986) The effects of sorbinil or peripheral nerve conduction velocity, polyol concentrations and morphology in the streptozotocin-diabetic rat. Diabetologia 29: 168-174

29. Cameron NE, Cotter MA, Robertson S (1989) The effect of aldose reductase inhibition on the pattern of nerve conduction deficits in diabetic rats. Q J Exp Physiol 74: 917-926

30. Robison WG, Kador PF, Akagi Y (1986) Prevention of basement membrane thickening in retinal capillaries by a novel inhibitor of aldose reductase, tolrestat. Diabetes 35:295-299

31. Cameron NE, Cotter MA, Robertson S (1989) Contractile properties of cardiac papillary muscle in streptozotocin-diabetic rats and the effects of aldose reductase inhibition. Diabetologia 32: $365-370$

32. Cameron NE, Cotter MA, Robertson S (1990) Changes in skeletal muscle contractile properties in streptozotocin-induced diabetic rats and role of polyol pathway and hypoinsulinemia. Diabetes 39: 460-465

33. Yasuda H, Sonobe M, Yamashita Met al. (1989) Effect of prostaglandin $\mathrm{E}_{1}$ analogue TFC 612 on diabetic neuropathy in streptozocin-induced diabetic rats. Comparison with aldose reductase inhibitor ONO 2235. Diabetes 38: 832-838

34. Williamson JR, Chang K, Tilton RG et al. (1987) Increased vascular permeability in spontaneously diabetic BB/W rats and in rats with mild versus severe streptozotocin-induced diabetes: prevention by aldose reductase inhibitors and castration. Diabetes 36: 813-821

35. Law SC, King RG (1990) Effects of ponalrestat on depressor responses to arachidonic acid in streptozotocin-diabetic rats. Gen Pharmacol 21: 135-139

36. Boulton AJM, Levin S, Comstock J (1990) A multicentre trial of the aldose-reductase inhibitor, tolrestat, in patients with symptomatic diabetic neuropathy. Diabetologia 33: 431-437

37. Stribling D, Mirrlees DJ, Harrison HE, Earl DCN (1985) Properties of ICI 128, 436, a novel aldose reductase inhibitor and its effects on diabetic complications in the rat. Metabolism 34: 336-344

38. Cameron NE, Cotter MA, Robertson S, Cox D (1992) Muscle and nerve dysfunction in rats with experimental galactosaemia. Exp Physiol 77:89-108

39. Moore PK, al-Swayeh OA, Chong NWS, Evans RA, Gibson A (1990) $\mathrm{L}-\mathrm{N}^{\mathrm{G}}$-nitro arginine (L-NOARG), a novel, L-arginine-reversible inhibitor of endothelium-dependent vasodilation in vitro. Br J Pharmacol 99: 408-412

40. Pfaffman MA, Ball CR, Darby A, Hilman R (1982) Insulin reversal of diabetes-induced inhibition of vascular contractility in the rat. Am J Physiol 242: H490-H495

41. Hagen AA, Shirasawa $Y$, White RP (1985) Experimental diabetes: reduction of serotonin-induced vasoconstriction by meclofenamic acid in vitro. Pharmacology 30:197-204

42. MacLeod KM, McNeill JH (1985) The influence of chronic experimental diabetes on contractile responses of rat isolated blood vessels. Can J Physiol Pharmacol 63: 52-57

43. Sullivan S, Sparks HV (1979) Diminished contractile response of aortas from diabetic rabbits. Am J Physiol 236: H301-H306
44. Owen MP, Carrier GO (1980) Calcium dependence of norepinephrine-induced vascular contraction in experimental diabetes. J Pharmacol Exp Ther 212: 253-258

45. Austin CE, Chess-Williams R (1991) Diabetes-induced changes in cardiac $\beta$-adrenoreceptor responsiveness: effects of aldose reductase inhibition with ponalrestat. Br J Pharmacol 102: 478 482

46. Penpargkul S, Fein F, Sonnenblick EH, Scheuer J (1981) Depressed cardiac sarcoplasmic reticular function from diabetic rats. J Mol Cell Cardiol 13: 303-309

47. Eibschutz B, Lopaschuk GD, McNeill JH, Katz S (1984) $\mathrm{Ca}^{2+}$ transport in skeletal muscle sarcoplasmic reticulum of the chronically diabetic rat. Res Comm Chem Path Pharmacol 45: 301-304

48. Heygler CE, Prakash A, McNeill JH (1987) Alterations in cardiac sarcolemmal $\mathrm{Ca}^{2+}$ pump activity during diabetes mellitus. Am J Physiol 252: $\mathrm{H} 540-\mathrm{H} 544$

49. Pieper GM, Gross GJ (1990) Augmented vascular relaxation to KT-362 in diabetic rat aorta: comparison to diltiazem. J Cardiovasc Pharmacol 16: 394-400

50. Moore SA, Bohlen HG, Miller BG, Evan AP (1985) Cellular and vessel wall morphology of cerebral cortical arterioles after shortterm diabetes in aduit rats. Blood Vessels 22: 265-277

51. Tesfamariam B, Brown ML, Deykin D, Cohen RA (1990) Elevated glucose promotes generation of endothelium-derived vasoconstrictor prostanoids in rabbit aorta. J Clin Invest 85:929-932

52. Hawthorne GC, Bartlett K, Hetherington CS, Alberti KGMM (1989) The effect of high glucose on polyol pathway activity and myoinositol metabolism in cultured human endothelial cells. Diabetologia 32: 163-166

53. Moncada S, Palmer RJM, Higgs EA (1989) Biosynthesis of nitric oxide from L-arginine. Br J Pharmacol 38: 1709-1715

54. Mirrlees DJ, Ward WHJ, Sennitt CM et al. (1991) Sulphonylnitromethanes - novel inhibitors of aldose reductase. Diabetologia 34[Suppl 2]: A21 (Abstract)

55. Griffith TM, Edwards DH, Newby AC, Lewis MJ, Henderson AH (1986) Production of endothelium-derived relaxant factor is dependent on oxidative phosphorylation and extracellular calcium. Cardiovasc Res 20:7-12

56. Weir CJ, Gibson IF, Martin W (1991) Effects of metabolic inhibitors on endothelium-dependent and endothelium-independent vasodilation of rat and rabbit aorta. Br J Pharmacol 102: 162-166

57. Richards JM, Gibson IF, Martin W (1991) Effects of hypoxia and metabolic inhibitors on production of prostacyclin and endothelium-derived relaxing factor by pig aortic endothelial cells, $\mathrm{Br} \mathrm{J}$ Pharamcol 102: 203-209

58. Davidson WS, Murphy DG (1985) Aldehyde reductases and their involvement in muscular dystrophy. In: Flynn TG, Weiner $\mathrm{H}$ (eds) Enzymology of carbonyl metabolism 2: aldehyde dehydrogenase, aldo-keto reductase, and alcohol dehydrogenase. AR Liss Inc, New York pp 251-263

59. Loven $\mathrm{DH}$, Schedl H, Wilson $\mathrm{H}$ et al. (1986) Effects of insulin and oral glutathione on glutathione levels and superoxide dismutase activities in organs of rats with streptozotocin-induced diabetes. Diabetes 35: 503-507

60. Kashiwagi A, Kikkawa R (1991) Abnormal glutathione redox cycle in cultured human endothelial cells for the pathogenesis of diabetic vascular complication. In: Rifkin $\mathrm{H}$, Colwell JA, Tavlor SI (eds) Diabetes 1991. Excerpta Medica, Elsevier, Amsterdam, New York pp 679-682

61. Jiang Z-Y, Woollard ACS, Wolff SP (1990) Hydrogen peroxide production during experimental protein glycation. FEBS Lett 268:69-71

62. Gryglewski RJ, Palmer RMJ, Moncado S (1986) Superoxide anion is involved in the breakdown of endothelium-derived vascular relaxing factor. Nature 320: 454-456

63. Bucala R, Tracey KJ, Cerami A (1991) Advanced glycosylation products quench nitric oxide and mediate defective endothelium-dependent vasodilation in experimental diabetes. J Clin Invest 87: $432-438$

64. McVeigh G, Brennan G, Johnston GD, Hayes R (1991) Impaired endothelium dependent and independent responses in non-in- 
sulin dependent diabetes mellitus. Diabetologia 34[Suppl 2]: A16 (Abstract)

65. Kumari K, Umar S, Bansal V, Sahib MK (1991) Inhibition of diabetes-associated complications by nucleophilic compounds. Diabetes 40: 1079-1084

66. Kamata K, Miyata N, Kasuya Y (1989) Functional changes in potassium channels in aortas from rats with streptozotocin-induced diabetes. Eur J Pharmacol 166:319-323

67. White RE, Carrier GO (1990) Vascular contraction induced by activation of membrane calcium ion channels is enhanced in streptozotocin-diabetes. J Pharmacol Exp Ther 253: 1057-1062

68. Nichols CG, Lederer WJ (1991) Adenosine triphosphate-sensitive potassium channels in the cardiovascular system. Am J Physiol 261: H1675-H1686

69. Kiff RJ, Gardiner SM, Compton AM, Bennett T (1991) The effects of endothelin- 1 and $\mathrm{N}^{\mathrm{G}}$-nitro-L-arginine methyl ester on regional haemodynamics in conscious rats with streptozotocininduced diabetes mellitus. Br J Pharmacol 103:1321-1326
70. Kiff RJ, Gardiner SM, Compton AM, Bennett T (1991) Selective impairment of hindquarters vasodilator responses to bradykinin in conscious Wistar rats with streptozotocin-induced diabetes mellitus. Br J Pharmacol 103: 1357-1362

71. Rosen R, Beck E, Rosen P (1988) Early vascular alterations in the diabetic rat heart. Acta Physiol Hung 72:3-11

Received: 29 April 1992

and in revised form: 30 June 1992

\section{Dr. N.E. Cameron,}

Department of Biomedical Sciences,

University of Aberdeen,

Marischal College,

Aberdeen AB9 1AS, UK 